Berkeley Law

From the SelectedWorks of Robert Cooter

June, 1994

Structural Adjudication and the New Law Merchant: A Model of Decentralized Law

Robert D. Cooter 


\title{
Structural Adjudication and the New Law Merchant: A Model of Decentralized Law ${ }^{1}$
}

\author{
ROBERT D. COOTER ${ }^{2}$ \\ University of California at Berkeley, Berkeley, California, USA
}

\section{Introduction \\ A. Legal Centrism}

The Soviet magazine Crocodile published a cartoon that depicted a cart containing one gigantic nail being pulled by some men, one of whom was saying to a bystander, "What's it for? We don't know what it's for, but it satisfies our nail quota for the month." This cartoon epitomizes the economic critique of central planning, according to which a planned economy does not generate the information or motivation required for economic efficiency. ${ }^{3}$ Like the workers in the cartoon, the people and enterprises under socialism often lack the knowledge and the will to produce valuable goods.

Central planning is a way of making law, as well as commodities. To implement the central plan, officials must have the power to allocate resources. To possess this power, the orders issued by planning officials at the top must trump the rights of property and contract enjoyed by people and enterprises at the bottom. Thus public law crowds out private law.

Only communist dictatorships have practiced central planning as a total system. However, democracies sometimes adopt procedures similar to central planning to solve specific economic problems. To illustrate, when Professor Richard Stewart stepped down recently from his position as the highest ranking environmental lawyer in the U.S. Department of Justice, he remarked that "America's environmental laws are based upon Soviet style centralized planning."4 He meant that America is trying to control pollution through a system of quotas imposed upon businesses by federal officials.

Such procedures have been called command-and-control regulations. ${ }^{5}$ The imperative theory of law, which has a long history in legal philosophy, defines law as a command backed by a threat. ${ }^{6}$ This tradition builds upon the fact that many laws impose obligations and attach sanctions to their violation. Similarly, the paradigm for centralized lawmaking is a decree, in which government officials formulate the state's goal, embody the goal in a rule, and force people to conform to it. Information and motivation move along a one-way street from the top to the bottom.

Rather than proceeding from top to bottom, lawmaking can proceed from bottom to top. Decentralized lawmaking has several forms. One form of decentralized lawmaking is to induce people to create a market by assigning property rights to them. To illustrate, environmental officials in the United States are now creating tradable emission rights, so that the market for emission rights will determine each firm's level of pollution. ${ }^{7}$ The subject of this article is another form of decentralized lawmaking:

(C) 1994 Butterworth-Heinemann 
enacting custom. For example, courts may determine fault and liability for accidents by applying the norms of the community in which the accident occurred. When courts apply community standards, they find law, rather than making it.

Many scholars have detected movement in modern history from decentralized to centralized law. Salmond concluded that customary law is important in the early stages of legal development but gradually cedes its place to statutes when "the state has grown to its full strength." 8 In a recent article, Ott and Schafer point out that modern German law has moved away from customary law and towards statutes. ${ }^{9}$ Many intellectuals believe that centralized law is inevitable, just as they once believed that socialism was inevitable.

In fact, centralized law, like socialism, is not even plausible for a technologically advanced society. The forces that reversed the trend towards socialism and destroyed central planning are also undermining legal centrism. An advanced economy involves the production of too many commodities for anyone to manage or regulate. As the economy develops, the information and incentive constraints tighten upon public policy. These facts suggest that as economies become more complex, efficiency demands more decentralized lawmaking, not less.

\section{B. New Law Merchant}

A community of people forms a social network whose members develop relationships with each other through repeated interactions. The modern economy creates many specialized business communities. These communities may form around a technology such as computer software, a body of knowledge such as accounting, or a particular product such as credit cards. Wherever there are communities, norms arise to coordinate the interaction of people. The formality of the norms varies from one business to another. Self-regulating professions, like law and accounting, and formal networks, like Visa, ${ }^{10}$ promulgate their own rules. Voluntary associations, like the Association of Home Appliance Manufacturers, issue guidelines. ${ }^{11}$ Informal networks, such as the computer software manufacturers, have inchoate ethical standards. I refer to all such norms of business communities as the new law merchant. ${ }^{12}$

The new law merchant arises outside of the state's apparatus for making law. However, lawmakers are pulled into the affairs of business communities by insiders who look to the state to resolve their disputes and make their laws, and lawmakers are pushed into the affairs of business communities by outsiders who seek to regulate private wealth and power. This article concerns the appropriate response of the state's lawmakers to these pulls and pushes.

The traditional account of the law merchant, from which the phrase the new law merchant is adapted, provides a model for how lawmakers might respond. The merchants in the medieval trade fairs of England developed their own rules and, in some cases, their own courts. However, as the English legal system became stronger and more unified, English judges increasingly assumed jurisdiction over disputes among merchants. The English judges did not know enough about these specialized businesses to evaluate alternative rules. ${ }^{13}$ Instead of imposing rules, the traditional history asserts that English judges tried to find out what practices already existed among the merchants and enforce them. Thus the judges dictated conformity to merchant practices, not the practices to which merchants should conform. By this process, the law merchant was allegedly absorbed into English common law. The pinnacle of this process is the development of the law of bills and notes in the 18th century by Judge Mansfield. ${ }^{14}$ 
I propose that modern lawmakers should respond to the new law merchant much like this response of the English common law courts to the old law merchant. However, modern lawmakers should take explicit account of insights from modern economics.

\section{Structural Approach}

Many legal reformers, such as the English utilitarians and the French exegetic school, have sought to replace common law with systematic statutes. ${ }^{15}$ The theory underpinning these reform proposals asserts that custom is regressive and statutes are, or can be, progressive. H. L. A. Hart noted that custom is not under anyone's rational control, so it cannot be directed to serve the ends of policymakers. Customs arise, whereas laws are made. He concluded that custom tends to be static and inefficient. ${ }^{16}$

This argument is unconvincing on its face. Why not argue that customs are dynamic and efficient because they can disappear without being repealed and they can change without being amended? Hart's understanding of custom resembles a socialist's understanding of markets. Socialists observe that prices arise, whereas plans are made, and conclude that markets must be inefficient because prices are not determined by deliberation and reasoning. This conclusion results from confusion about the difference between individual rationality and social efficiency. Individual rationality generally requires deliberation and planning, but social efficiency does not. Research in industrial organization shows that the efficiency or inefficiency of markets is often determined by their incentive structure. ${ }^{17}$ Similarly, the efficiency or inefficiency of custom often depends upon the incentive structure that produced it. In the language of game theory, the payoff matrix often determines the possible equilibria.

These facts suggest how lawmakers, especially courts, should respond to the new law merchant. First, the lawmakers should identify the actual norms that have arisen in specialized business communities. Second, the lawmakers should identify the incentive structures that produced the norms. Third, the efficiency of the incentive structures should be evaluated using analytical tools from economics. Those norms should be enforced that arise from an efficient incentive structure, as ascertained by structural tests that economists apply to games. I call this procedure the structural approach to adjudicating social norms.

The structural approach conflicts with much writing in the economic analysis of law in two respects. First, lawmakers following the structural approach infer the efficiency or inefficiency of a norm, rather than measuring it directly. In contrast, much of the economic analysis of law commends the evaluation of legal rules by cost benefit techniques. For example, at the end of his classic article entitled, "The Problem of Social Cost," ${ }^{8}$ Ronald Coase recommends that judges choose among alternative liability rules by comparing their costs and benefits. ${ }^{19}$

Second, the structural approach that I develop applies to obligations, not regularities. To illustrate the difference, men take off their hats when they enter a furnace room or a church. ${ }^{20}$ Taking off your hat to escape the heat is different from taking off your hat to satisfy an obligation. A mere regularity results from an inclination, not an obligation. Economic models seldom distinguish between an equilibrium sustained by inclination or obligation. However, people respond differently to changes in incentives, depending upon whether they are motivated by inclination or obligation, as I will show.

Having distinguished regularities from obligations, I can clarify the meaning of the word norm. Norm sometimes refers to a regularity in the behavior of people. This us- 
age is typical in sociology, where norms are contrasted with values. Among economists and philosophers, norm typically refers to a prescription about what people "ought" to do. I use the term to refer to a consensus in a community about what its members ought to do.

Norms arise in a game when it creates, or evokes, a sense of obligation in the players concerning the strategies that they follow. Explaining why some strategies are raised to the level of obligations, and others are not, requires a theory of games and norms, which I will now develop. The game theory draws upon recent developments in evolutionary economics. The theory of norms adapts some philosophical concepts to game theory. Finally, I will show how judges should use these theories in deciding cases.

\section{Games and Norms}

\section{A. The Investment Game}

The parties in a business network often cooperate together in order to make a product. Cooperation involves relying upon each other, and reliance creates the possibility for opportunism. By opportunism I mean an act in which someone destroys part of the cooperative surplus in order to secure a larger share of it. The first game that I develop will model cooperation and opportunism.

Consider the "investment game" depicted in Figure 1. The $1^{\text {st }}$ player to move decides whether or not to make an investment. If no investment is made, the game ends and the players receive nothing. If an investment is made, the $2^{\text {nd }}$ player decides whether to cooperate or appropriate. Cooperation by both players maximizes the joint payoffs (each player receives .5 ), but noncooperation by the $2^{\text {nd }}$ player maximizes his payoff (player 2 receives 1 , player 1 loses .25 ).

If the game is played only once, the best move for the $2^{\text {nd }}$ player is to appropriate. Knowing this, the best move of the $1^{\text {st }}$ player is not to invest. The one-shot game of investment has a unique solution, which is unproductive. I will now consider how to avoid this unproductive outcome without law or courts.

\section{B. Relationships}

Instead of one-shot transactions, investment in a business network often occurs among people with enduring relationships. To capture this possibility, assume that the investment game depicted in Figure 1 is repeated indefinitely often, thus transforming a one-shot game into a super game. In any round of the super game in which the $1^{\text {st }}$ player invests, the $2^{\text {nd }}$ player enjoys an immediate advantage from appropriating. A

\begin{tabular}{ccccc} 
& & & \\
& Cooperate & & \\
& & & Appropriate \\
\hline Invest & .5 & .5 & -.25 & 1.0 \\
& .5 & & & 0 \\
\hline Don't invest & 0 & 0 & 0 & \\
\hline
\end{tabular}

F1G. 1. Investment game 
successful strategy for preventing such opportunistic behavior, called $t i t$-for-tat, ${ }^{21}$ is for the $1^{\text {st }}$ player to respond in the next round by refusing to invest and to begin investing again in a subsequent round. The experience of immediate punishment, followed by a reward for changed behavior, usually suffices to stop opportunistic behavior by the $2^{\text {nd }}$ player and restore cooperation. Experimental evidence indicates that tit-fortat comes very close to maximizing a player's payoff in a variety of circumstances, and these empirical findings are generally supported by theory. ${ }^{22}$

The problem of cooperation is solvable in many repeated games when players commit to an enduring relationship, provided that they can observe each others' moves and they do not discount the future too heavily..$^{23}$ (The exceptions to this generalization need not concern us here. ${ }^{24}$ ) Enduring relationships can be based upon kinship, friendship, ethnicity, or religion, to name a few forms of commitment. Relationships substitute for state-enforced law in tribes, among criminals, in much international trade, under communism, and in informal business networks.

\section{Exit}

Instead of enduring commitments, many relationships in a business network dissolve and reform easily. To model tentative relationships, assume as before that the investment game is repeated indefinitely often. However, change the assumption that there are only two players. Instead, assume that there are indefinitely many players, who form into pairs to play each round of the game. At the end of each round, some of these partnerships continue in the next round and others dissolve. When a partnership dissolves, the players must find new partners for the next round of the investment game by a random draw from the pool of available players.

Partnerships dissolve in two ways. First, one of the partners may exit from the relationship. A partner is free to exit at the end of any round. Second, if neither partner exits, an exogenous random variable determines whether or not the relationship terminates. The exogenous random variable represents unforeseeable events. Thus a partnership can end deliberately (exit) or accidentally (termination). The investment game with exit is depicted in its extensive form in Figure 2.

The equilibrium concept for this kind of game draws upon evolutionary theory. ${ }^{25}$ Think of the "players" as hosts for competing behaviors and ask which of these behaviors will survive in competition with the others. Selection favors the behavior that enjoys a higher return. To model this fact, assume that the proportion of players us-

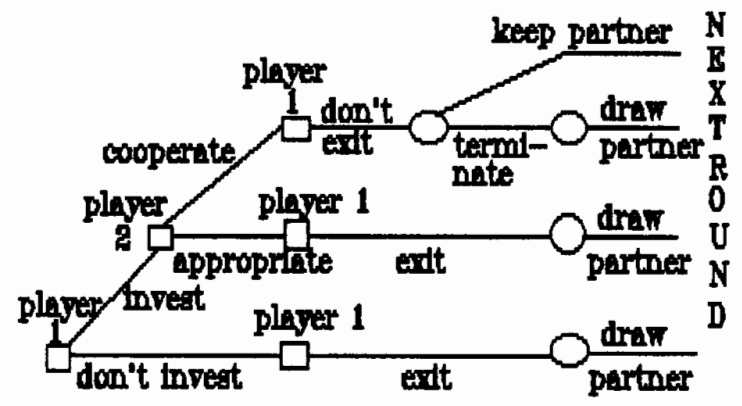

FIG. 2. Investment game with exit 
ing a particular strategy increases as long as it enjoys an above-average return. Conversely, the proportion of players using a particular strategy decreases as long as it suffers below-average returns. Competition tends to eliminate all below-average strategies, so that every strategy surviving in equilibrium earns the same rate of return.

When a payoff matrix like the one depicted above is embedded in an evolutionary model, a familiar result to theorists is a mixed equilibrium in which most players cooperate and some players behave opportunistically. ${ }^{26}$ To see why this result occurs, consider the fact that cooperators form stable relationships, whereas noncooperators only play once with any particular partner. ${ }^{27}$ Consequently, the player who follows the pure strategy of cooperation expects to enjoy a modest payoff in a high proportion of rounds, whereas the player who follows the pure strategy of noncooperation expects to enjoy a high payoff in a low proportion of rounds. In a mixed equilibrium, these two strategies have the same expected value.

\section{What Is a Norm?}

I have shown that relationships can solve the investment game through tit-for-tat or exit. In communities of people, however, such games usually generate norms. Before offering a theory of how norms arise, I sketch briefly what they are. The question, "What is a norm?" is even more general than the question, "What is a law?" These questions have been addressed by moral philosophers over many generations. I distill some conclusions relevant to behavioral theories.

Norms are practical in the sense that they direct behavior. To direct behavior effectively, a speaker ought to say who must do what and when. A complete norm provides these instructions explicitly. ${ }^{28}$ For example, drivers ought to remain within the posted speed limit or pay a fine. Notice that I use the term norm to refer to obligations, which conforms to standard usage among philosophers. Sociologists often use norm differently, to refer to any kind of social regularity, regardless of whether or not it is obligatory.

\section{E. Internalization}

The fact that a law was enacted provides a reason for citizens to do what it requires. Similarly, the fact that a norm was internalized provides a reason for the decision maker to do what it requires. To illustrate, suppose that I initially regard the decision to smoke as a purely personal preference, in which the individual should weigh immediate pleasure against future harm to his health. Someone subsequently convinces me, contrary to my previous beliefs, that smoking is morally wrong. ("God forbids us to harm ourselves for pleasure's sake," "You risk orphaning your child," etc.) After my conversion, I have an additional reason for not smoking, specifically the fact that smoking violates a moral rule that I now hold.

Psychologists have extensively researched the internalization of norms. Stages in the development of moral reasoning among children have been studied, notably by Piaget and Kohlberg. ${ }^{29}$ According to their theories, a child perfects the ability to internalize norms as it acquires a capacity for general reasoning. Their research, like my characterization of internalization as accepting a new reason for acting, makes the process sound cool and rational. In contrast, "depth psychology" often traces the internalization of morality to irrational processes that are hot and inchoate. According to these 
theories, internalization of morality ingrains new impulses in a child through emotional experiences. An example is Freud's theory that morality is the "ghost in the nursery," meaning the repressed memory of parental punishments. ${ }^{30}$

Both types of internalization-accepting a new reason and ingraining a new impulse-create a new motive, which can tip the individual's motivational balance. Economic models often view motivation as a calculus of psychological benefits and costs. ${ }^{31}$ From this perspective, internalization can change the sign of the net psychological benefits attached to an act.

To illustrate, consider how the payoffs in Figure 1 might change if the $2^{\text {nd }}$ player internalizes a norm forbidding the appropriation of the $1^{\text {st }}$ player's investment. ${ }^{32}$ Someone who has internalized a norm feels guilt from violating it and worthiness from obeying it. ${ }^{33}$ After internalizing the norm, the $2^{\text {nd }}$ player might experience a cost of 7 from violating it, so the net payoff from appropriating now equals .3, as depicted in Figure 3. Cooperation is the dominant strategy for both players in Figure 3.

\section{F. Existence}

How can an observer tell whether a custom exists in a community of people? For a community to have a custom, a significant proportion of its members must internalize it. Customary norms direct the behavior of people who internalize them. Consequently, a customary norm that achieves a minimum level of effectiveness in directing behavior exists in a community. Otherwise, the community does not have the customary norm in question. This conclusion, which is the core of the positive theory of law, ${ }^{34}$ provides a building block in the theory of norms and games. (The many refinements and criticisms of the positivist theory of norms need not concern us. ${ }^{35}$ )

The preceding analysis suggests a prescription for the empirical investigation of customs. First, formulate the hypothesis that a customary norm exists. To do so, state who is obligated to do what in which community. Second, to test whether the hypothesis is true or false, collect information from the community concerning the internalization of the norm. The hypothesis that a customary norm exists in a community is true if a sufficient number of its members internalize the norm.

The behavior of people reveals whether they have internalized a norm. As explained, internalization strengthens motivation and may tip the balance in decision making. In addition, someone who has internalized a norm feels that others ought to conform to it, so he tends to praise conformists and criticize violators. Later I show that this fact is central to the change in an equilibria caused by players' internalizing a norm.

\begin{tabular}{|c|c|c|c|c|c|}
\hline & & & & & \\
\hline & & & & & riate \\
\hline & Invest & & .5 & & 0.3 \\
\hline & & .5 & & -.25 & \\
\hline & Don't invest & & 0 & & 0 \\
\hline & & 0 & & 0 & \\
\hline
\end{tabular}

FIG. 3. Internalization and investment game 


\section{G. Thick Self}

Figure 1 describes the objective payoffs of the players in the investment game. Figure 3 describes the subjective payoffs of the players in the investment game after internalizing a norm. The possibility of internalizing morality creates a tension between two different kinds of self-interest. The simplest kind of self-interest, which I call thin self-interest, looks only to objective payoffs in terms of wealth or power, as in Figure 1. The more complex kind of self-interest, which I call thick self-interest, modifies objective payoffs to take account of the subjective value of morality, as in Figure 3.

The decision makel .n economic theory is often described as "perfectly rational," which means that he is completely instrumental in pursuing explicit ends. The decision maker in legal theory is often described as "completely reasonable," which means that he has fully internalized community norms. The rational actor's self-conception is thin, whereas the reasonable actor's self-conception is thick.

Thin self-interest and thick self-interest sometimes conflict with each other by prompting incompatible actions. For example, Figure 1 prompts the $2^{\text {nd }}$ player to appropriate, and Figure 3 prompts the $2^{\text {nd }}$ player to cooperate. Internal conflict, which is the subject of much moral philosophy, has only recently found its way into economic models..$^{36}$ Instead of discussing models, however, I want to describe an important connection between morality and business.

Max Weber argued that the emergence of capitalism depended upon an ethic, first perfected among Protestant Christians, ${ }^{37}$ in which the individual internalized an occupational role. Internalization here means accepting the norms of an occupation so intimately that they become part of the individual's self-conception, thus altering his perceived self-interest. Internalization of an occupational role, according to Weber, increases the dedication and creativity with which individuals pursue business goals. According to Weber, the best workers express themselves through their jobs. In general, pursuit of thick self-interest is expressive because acting displays the values internalized by the actor. In contrast, pursuit of thin self-interest is purely instrumental.

Internalization of a norm dispenses with the need for state enforcement, so internalization is the ultimate form of decentralization. Thus the internalization of occupational roles is critical to decentralizing economic law.

\section{H. Marginal Cooperator}

If some people internalize a cooperative norm, will the equilibrium level of investment and production increase? I will demonstrate that individuals typically change the evolutionary equilibrium by punishing violators of the norm, but not by conforming to it themselves.

In an evolutionary equilibrium, all strategies that persist yield the same objective - payoff. In a mixed equilibrium, some players pursue the strategy of cooperation, and others pursue the strategy of appropriation. Consequently, the strategies of cooperation, and appropriation yield the same objective payoff in a mixed evolutionary equilibrium. Since the payoff is the same, some players will conform to the norm without internalizing it. I use the term adventitious to describe players who conform to a norm without internalizing it.

I have explained that adventitious cooperation occurs in a mixed evolutionary equilibrium in the investment game. When a mixed evolutionary equilibrium is disturbed, a new one is reached by adjusting the number of adventitious cooperators. To illus- 
trate, assume that the rate of return equalizes for cooperators and appropriators in the investment game when 80 players cooperate and 20 players appropriate. Furthermore, assume that 50 of the 80 cooperators internalize the norm, whereas 30 players cooperate adventitiously. Now assume that one of the appropriators internalizes the norm. By hypothesis, internalization by an appropriator has two effects. First, he stops appropriating and starts cooperating (Figure 3), so that 81 players cooperate and 19 players appropriate. Second, the number of players who are willing to bear the cost of punishing appropriators increases from 50 to 51 .

Let us separate these two effects for purposes of analysis. Assume for the moment that punishing appropriators is infeasible, so the $2^{\text {nd }}$ effect is nil. Appropriators have decreased from 20 to 19 , and cooperators have increased from 80 to 81 . If the system is stable, the increase in the ratio of cooperators to appropriators will cause a fall in the payoff of cooperators relative to appropriators. One of the adventitious cooperators will respond by changing his strategy from cooperation to appropriation. His change in strategy will restore the equilibrium in which there are 20 appropriators and 80 cooperators, and both strategies earn the same payoff. After these changes, one person cooperates who formerly appropriated, and one person appropriates who formerly cooperated. In general, when punishment is ineffective, the internalization of a norm changes the identity, but not the number, of cooperators in a mixed evolutionary equilibrium.

To clarify this conclusion, I restate it in different language. A small change in objective payoffs causes marginal players to change their strategy, whereas inframarginal players persist in their current strategy. In a mixed evolutionary equilibrium, adventitious cooperators are marginal, whereas cooperators who internalize the norm are inframarginal. A change in the number of inframarginal players in a game does not change the equilibrium, which is determined by marginal players.

Now I turn to the $2^{\text {nd }}$ effect of internalization, which, unlike the $1^{\text {st }}$ effect, changes the equilibrium level of cooperation. In the preceding example, I assumed that one of the appropriators internalized the norm. Instead, I now assume that one of the adventitious cooperators internalizes the norm. After this event, there are 29 adventitious cooperators and 51 principled cooperators. A person who internalizes a norm is willing to devote modest amounts of his resources to enforcing it. An increase in the resources available to enforce the norm causes a fall in the relative payoff to appropriators. Consequently, one or more of the appropriators will switch to cooperation. If the game is stable, this increase in the number of cooperators will decrease their relative payoff, and equilibrium will be restored at a higher ratio of cooperators to appropriators than originally, say, 81:29. In general, people who internalize norms are marginal with respect to enforcement efforts, whereas people who do not internalize norms are inframarginal.

.How much informal enforcement of norms is possible in fact? Anthropology documents the enforcement of norms without the support of the state, or even with its opposition. For example, squatters who occupy land illegally in Papua New Guinea sometimes hire lawyers to draft real estate "contracts" for buying and selling land that actually belongs to someone else. ${ }^{38}$ The existence of such contracts provides facts to sway public opinion within close ethnic communities. Empirical studies of community life and business practice have often concluded that informal sanctions are more important than the law in enforcing norms. ${ }^{39} \mathrm{I}$ take these studies as proof that informal enforcement works as modern economies must rely upon decentralization of norms. 


\section{Emergence of a Norm}

Having explained the effects of internalization, now I briefly explain its causes. Under certain circumstances, cooperation by a player in the investment game benefits everyone in a business community. ${ }^{40}$ In these circumstances, some members of the community will say that people ought to cooperate for the sake of the public good. It is easy to see why no one will publicly disagree. The investor will not invest unless he thinks that his partner is likely to cooperate. People signal what they will do by what they say. To signal cooperation, each person will say that everyone ought to cooperate, even if the speaker plans to appropriate. Unanimous endorsement of cooperation will convince some members of the community to internalize the obligation, and to inculcate it in the young. When a public consensus forms that people ought to cooperate, and when enough people internalize the obligation to punish noncooperators effectively, a social norm exists in a community. (This proposition is central to the positive theory of norms in philosophy. ${ }^{41}$ ) Thus a social norm will evolve in a community when private incentives for signaling align with a local public good.

By contrast, consider what happens when private incentives to signal align with a local public bad. To be concrete, assume a bargaining game in which the players can create a surplus by agreeing upon how to divide it. Soft bargainers benefit others by making concessions that facilitate agreement, so soft bargaining is a public good. Hard bargainers harm others by demanding concessions that impede agreement, so hard bargaining is a public bad. To extract concessions, hard bargainers will want to signal their strategy. Even soft bargainers may want to disguise their strategy by signaling that they are hard bargainers. Players who want to signal that they bargain hard will say that everyone is free to follow his self-interest, rather than being obligated to bargain soft. While some people may say that everyone ought to bargain soft for the sake of others, this view cannot command a consensus among players. Without a consensus concerning what people ought to do, a social norm does not exist in a community. The alignment of incentives to signal with a local public bad blocks the evolution of a social norm.

I have argued that a social norm will evolve in a community when private incentives for signaling align with a local public good and that a norm will not emerge when incentives to signal align with a public bad. Instead of supplying public goods or public bads, many acts are private in the sense that they do not affect others. The regulation of private acts by social norms is extensive in some kinds of communities, especially churches. These norms express a preferred way of life and a moral ideal for the person. In contrast, many business communities that focus on the advantages of free exchange and the making of money have little concern with the private acts of its members. Such free business communities do not develop norms regulating purely private goods.

My consideration of public goods, public bads, and private goods points to the conclusion that a necessary and sufficient condition for the evolution of a social norm in a free business community is alignment of private incentives for signaling with a local public good. I call this proposition the alignment theorem. ${ }^{42}$

\section{J. Efficiency of Norms}

I will use the alignment theorem to develop a theory of efficient norms. Many games have inefficient equilibria, which are sometimes called evolutionary traps. ${ }^{43}$ Social norms 
evolve through a process of discussion, which often exposes evolutionary traps. Evolutionary traps often occur because the best strategy for each individual benefits him less than it harms other players. According to the alignment theorem, a community will not develop social norms supporting strategies that harm its members. Once exposed, a strategy leading to an evolutionary trap may be censured by a community, or tolerated, but not encouraged. In other words, a consensus will not arise in the community that its members ought to follow a strategy leading to an evolutionary trap. Consequently, many of the inefficient strategies in games cannot be supported by social norms. This fact gives human communities, which have morality, an advantage over animal communities, which lack morality to protect them from evolutionary traps. ${ }^{44}$

However, there are special circumstances in which a community may develop a social norm that harms its members. Decentralized processes economize on information by making local improvements. One kind of evolutionary trap occurs when local progress is global regress. To illustrate, suppose that some climbers try to ascend a mountain in a fog by following the rule, "Always go up." If the mountain has a single peak, this rule will get them to the summit. If the mountain has several false peaks, this rule will get the climbers to a local peak, but not necessarily to the summit. In technical terms, local improvements lead to a global maximum on a convex surface, whereas local improvements lead to a local maximum on a nonconvex surface.

A historical example shows the problem that nonconvexity creates for decentralized law. Everyone in a country drives on the same side of the road, but historical accident determined whether it is the left, as in Britain, or the right, as in most other countries. Given a world economy, it would be better for the British to drive on the right like almost everyone else. However, driving on the left is a stable equilibrium, which will not change without central direction. Large nonconvexities hide traps from people, which can cause the wrong norm to emerge. ${ }^{45}$ The critics of the common law claim, in effect, that it is a vast collection of rules similar to "Drive on the left."

The alignment theorem uses the phrase local public good to refer to benefits that an actor conveys on other members of the community in which a norm arises. However, sometimes the norms of one community affect another community. A community norm has positive or negative spillovers when obeying it conveys benefits or costs to neighboring communities. Communities often develop norms that benefit their members at the expense of members of other communities. To illustrate, suppose a consumer writes a large check that is diverted by accident or fraud, resulting in a large loss that must be borne by the consumer or his bank. Since the lost check is large, its value may exceed the value of the future relationship between the bank and its customer. Under these circumstances, a bank may wish to shift the loss to its customer. Foreseeing such possibilities, an association of banks may proclaim that its members should hold customers liable for large check losses. In general, norms regulating liability may externalize the costs of one community on another.

Another example concerns monopoly practices. A cartel can maximize the total profits of its members by setting the same price as a monopolist. If a member of the cartel "cheats" by secretly discounting prices, the cheater's profits will increase by less than the fall in profits of the other cartel members. ${ }^{46}$ In response to this fact, a cartel may develop norms to sanction cheaters. These norms will help the "community" of producers in the cartel to maximize their profits. However, the gain in profits to sellers is less than the fall in consumer's surplus to buyers. Such monopoly practices are inefficient from the perspective of the society as a whole. 
Racial discrimination in markets provides a sinister example of such a cartel. Discrimination permits one community to reduce competition from another, which benefits the dominant group at the expense of the subordinate group. However, each individual member of the cartel can profit from violating the norm requiring them to discriminate. For example, if the racial cartel reserves certain high-paying jobs for the dominant group, an employer can profit from hiring qualified workers in the subordinate group to do the same job for less pay. To deter such "cheating," the racial cartel must punish members who violate its norms. Like other cartels, racial cartels attempt to overcome their natural instability by enacting their norms into law. ${ }^{47}$

The preceding discussion of efficient norms is incomplete in a variety of ways. ${ }^{48}$ Nevertheless, I reach the tentative conclusion that strategies that evolve into social norms in a free business community will be efficient in the absence of nonconvexities or spillovers to other communities. I call this theorem weak utilitarianism. ${ }^{49}$

\section{K. Structural Approach to Adjudicating Social Norms}

I have developed a theory of the evolution and efficiency of social norms. According to this theory, specialized business is often organized so that norms emerge from repeated transactions. These norms impose an obligation upon members of the community to follow strategies that benefit other members of it. Self-interest compels everyone to enforce these norms by such means as tit-for-tat and exit. However, the benefits of enforcing these norms diffuse throughout the community, so self-interest results in underenforcement. The tendency of individuals to free-ride on the enforcement efforts of others is partly overcome by internalization of the norms. Internalization causes people to go beyond self-interest in expending resources on enforcement. However, informal enforcement often stops short of the optimal level, where the marginal cost of enforcement equals the marginal benefit. Optimal deterrence requires supplementing informal sanctions with legal sanctions.

This theory suggests the correct role of the state with respect to custom. The court can benefit business and improve its efficiency by enforcing its norms against violators. The role of the state in a decentralized legal system is to elevate appropriate social norms to the level of law. Elevating a social norm to the level of law involves issuing an authoritative statement of the norm and backing it with the state's coercive power. The "adjudication of social norms" describes the process by which officials decide which social norms to elevate to the level of law.

I envision three steps in adjudicating business norms. First, lawmakers should identify the actual norms that have arisen in business communities. A norm exists in a community when there is a consensus about what its members ought to do. Identifying a social norm involves finding evidence that people have internalized an obligation, especially their willingness to enforce it upon violators. Second, lawmakers should identify the incentive structures that produced the norms. Identifying the incentive structure requires constructing a model that characterizes the norm as an equilibrium in a game and testing the model against the facts. Third, the efficiency of the incentive structure should be evaluated using analytical tools from economics. When the incentive structure is efficient, the social norm imposes an obligation to follow a cooperative strategy that results in repeated transactions. Furthermore, the payoff sets are convex, and the effects of the obligatory strategy do not spill over beyond the community in which the norm arose. Those business norms that arise from an efficient incentive structure should be enforced by the state. 
The structural approach conflicts with much writing in the economic analysis of law in two respects. First, the structural approach applies to obligations, not mere regularities. In contrast, most economic models do not distinguish equilibria sustained by obligation from equilibria sustained by inclination. Second, lawmakers following the structural approach infer the efficiency or inefficiency of a norm, rather than measuring it directly. In contrast, much of the economic analysis of law commends the evaluation of legal rules by cost benefit techniques.

\section{Conclusions}

"Is the price and quantity of shoes efficient?" A direct answer can be found by a costbenefit analysis of shoe production. However, economists know that the necessary information is unavailable to perform such an analysis. ${ }^{50}$ Consequently, economists try to answer the question indirectly by discussing market structure and firm behavior. Unfortunately, the proponents of economic analysis do not show the same respect for information constraints applicable to law. "Is a community standard of precaution efficient?" Theorists typically commend that judges answer this question by applying cost-benefit techniques like the Hand Rule. The application of cost-benefit techniques requires more information about cost than courts usually possess. Economic specialization constantly widens the information deficit for courts. To overcome the deficit, adjudication requires a structural approach. In a structural approach, the courts decide whether to enforce a social norm by inquiring into the incentives by which it arose, rather than attempting to weigh costs and benefits directly. A structural approach is more decentralized because lawmakers must rely upon social institutions to create social norms.

The structural approach bears upon an old debate in jurisprudence about whether judges make law or find it. Scholars generally accept that American courts make law in light of public policy. The older conception that judges find law has been largely abandoned. The theory of games and norms can revitalize the older conception of common law. According to the theory developed in this article, a common law court should find that a social norm is law if it evolved from an appropriate incentive structure. An appropriate incentive structure is one in which incentives for signaling by individuals align with the public good (long-run relations, convexity, no spillovers). Social norms that evolve from an appropriate incentive structure already have the community's authority in them. Recovering this conception grows more urgent as the economy's complexity increases.

\section{Notes}

1. I am grateful for comments from Wolfgang Fikentscher, Paul Edwards, Judge Richard Posner, Dan Rubinfeld, Hans-Bernd Schafer, Claus Ott, Goran Hagg, and participants in the Conference on European Corporate Law, Vitznau, Switzerland, September 1993. This article draws upon an earlier paper entitled, "The Structural Approach to Adjudicating Social Norms: Evolution of the Common Law Reconsidered" (John M. Olin Working Papers in Law and Economics, School of Law, University of California at Berkeley, \#90-5, fall 1990).

2. Professor of Law, University of California at Berkeley.

3. This critique was developed in the 1930s in the debate between Lange and Lerner. See Oscar Lange, "On the Economic Theory of Socialism," 4 Review of Economic Studies 60-66 (1936); Oscar Lange and Fred M. Taylor, On the Economic Theory of Socialism (Minneapolis, MN, U. Minnesota 
Press, 1938); Abba Lerner, The Economics of Control (The Macmillan Company, New York, 1944), Chapter 3.

4. I am grateful to Professor Don Elliott of Yale University for this quotation.

5. Stephen Breyer, Regulation and Its Reform (Cambridge, MA, Harvard U.P., 1982); Charles Schultze, The Public Use of Private Interest (Washington, D.C., B rookings, 1977).

6. Alternatively, this tradition defines a law as an order backed by a threat. For a review of this tradition, see Joseph Raz, The Concept of a Legal System (2nd ed., New York, Oxford U.P., 1980).

7. For a review of theory and practice, see Tom Tietenberg, Environmental and Natural Resource Economics (2nd ed., Glenview, IL, Scott, Foresman, 1988). Other examples of law-inducing markets are patent and copyright law.

8. John William Salmond, Jurisprudence (12th ed., London, Sweet \& Maxwell, 1966). See his discussion of the issue on pp. 66-67.

9. Claus Ott and Hans-Bernd Schafer, "Emergence and Construction of Efficient Rules in the Legal System of German Civil Law" (Paper presented to European Law and Economics Association meeting, Copenhagen, August 1991). In making these remarks, they are describing history, not passing judgment upon it.

10. The Visa payments network is actually divided into two corporations with different operating rules, one for American transactions and the other for international transactions.

11. David Hemenway, Industrywide Voluntary Producer Standards (Cambridge, MA, Ballinger, 1975).

12. The term has also been applied more restrictively to norms of international trade invoked in arbitration and mediation.

13. Wolfgang Fikentscher once remarked, "The decisions of the Munich traffic court of appeals concerning motor vehicle accidents improved markedly after the judges learned to drive."

14. The traditional theory is developed by James Holden in The History of Negotiable Instruments in English Law (London, Althone Press, 1955). Holden is criticized in John Baker in "The Law Merchant and the Common Law Before 1700," 38 Cambridge Law J. 295 (1979). A revised view, which stresses that Mansfield immersed himself in the minutiae of business practice in order to extract the best principles from it, is found in Jim Rogers, The Early History of the Law of Bills and Notes: A Study of the Origins of Anglo-American Commercial Law (Cambridge UP, forthcoming). I am grateful to Jim Rogers for discussing these points with me.

15 For complete references on the French exegetic school and the lex mercatoria, see F. Dely, Intermational Business Law and Lex Mercatoria (Amsterdam, North-Holland, 1992).

16 H. L. A. Hart, Concept of Law (Oxford, Clarendon Press, 1961), pp. 89-96.

17 One of the intellectual foundations of American antitrust law is the distinction between industry structure, the conduct of firms, and economic performance. See Joe Bain, Industrial Organization (2nd ed., New York, Wiley, 1968) or Richard Caves, American Industry: Structure, Conduct, Performance (3rd ed., Englewood Cliffs, NJ, Prentice-Hall, 1972). This distinction came under attack as game theory was applied to industrial organization. My term structural approach refers to the incentive structure of games, not the competitiveness of markets.

18 Ronald Coase, "The Problem of Social Cost," 3 Journal of Law and Economics 1 (1960).

19 An exception to the enthusiasm for judicial cost-benefit analysis is Richard Epstein's view that judges ought not to have so much discretion. See "The Rule of Risk/Utility," 48 Ohio State Law Journal 469 (1987) at 470.

20. Equivalently, men put on a hat in a snowstorm or a synagogue.

21. R. Axelrod, The Evolution of Cooperation (New York, Basic Books, 1984).

22. Maskin and Fudenberg have proved that in any game in which (1) players maximize the discounted sum of single-period utilities, (2) the discount rate is not too high, and (3) the players can observe the past history of moves in the game, any pair of payoffs that Pareto-dominate the minimax can arise as average equilibrium payoffs of the repeated game. Thus repetition of the game makes a Pareto improvement possible. This theorem, however, still leaves unexplained why the probability of a Pareto-efficient solution is as high as empirical studies suggest it to be. See Drew Fudenberg and Eric Maskin, "The Folk Theorem in Repeated Games with Discounting, or With Incomplete Information," 54 Econometrica 533-554 (1986).

An element of mystery also surrounds the "end-game" problem. If a game of distribution is repeated an infinite number of times, cooperation is individually rational. If, however, such a game 
is repeated a finite number of times, "cheating" on the last round is individually rational. But if cheating is individually rational on the last round, it is also individually rational on the next to last round, and so forth. Thus strict individual rationality causes the game to unwind. If, however, the players are willing to settle for a strategy that is very close to the self-interested maximum, but a little short of it, the end-game problem can be solved and the players will cooperate. In general, see Avinash Dixit and Barry Nalebuff, Thinking Strategically: The Competitive Edge in Business, Politics, and Everyday Life (New York, Norton Press, 1991), and Drew Fudenberg and Jean Tirole, Game Theory (Cambridge, MA, MIT Press, 1991).

23. Axelrod, op. cit.

24. See especially the "weakest link in the chain" game, Glenn W. Harrison and Jack Hirshleifer, "An Experimental Evaluation of Weakest Link/Best Shot Models of Public Goods," $97 \mathrm{~J}$. Political Econ. 201-225 (1989), and Jack Hirshleifer and Juan Carlos Martinez Coll, "What Strategies Can Support the Evolutionary Emergence of Cooperation?" 32 J. Conflict Resolution 367-398 (1988).

25. For an excellent review of these developments, see Abhijit Bannerjee and Jorgen W. Weibull, "Evolution and Rationality: Some Recent Game-Theoretic Results Research Papers in Economics"

26. See Rudolf Schussler, “Anonymous Exchange Cooperation," paper presented at 4th International Conference on Social Justice Research, July 1993, Trier, Germany.

27. For this formulation, see Schussler, preceding note, and also Robyn Dawes and John Orbell, "Social Welfare, Cooperators' Advantages, and the Option of Not Playing the Game." Paper presented at 4th International Conference on Social Justice Research, July 1993, Trier, Germany.

28. Thus the canonical form of a norm, according to one formulation, states that each member of a certain class of people (norm's subjects) has an obligation (norm's character) to do something (norm's act) in certain circumstances (norm's conditions), subject to a penalty for noncompliance (norm's sanction). Here I follow Georg Henrik von Wright's account of the "kernel" of a norm in Norms and Action (London, Routledge, 1968). Other elements could be added to the canonical form of a norm, including the enforcer of the norm and whether the enforcer is permitted or obligated to enforce it.

29. Lawrence Kohlberg, "Moral Stages and Moralization: The Cognitive-Developmental Approach," Moral Development and Behavior: Theory, Research, and Social Issues (New York, Holt, Rinehart and Winston, 1976), ed. Thomas Lickona, pp. 31-53; "Stage and Sequence: The CognitiveDevelopment Approach to Socialization," in D. A. Goslin, ed., Handbook of Socialization Theory and Research (Chicago, Rand McNally, 1969); L. Kohlberg, The Philosophy of Moral Development: Moral Stages and the Idea of Justice (San Francisco, Harper \& Row, 1981); "Appendix. The Six Stages of Moral Judgment," The Philosophy of Moral Development: Essays on Moral Development, Volume I(1981), pp. 409-412. Flaws in Kohlberg's approach have generated much criticism from feminists, notably Carol Gilligan, In a Different Voice: The Psychology of Women's Development (Cambridge, MA, Harvard U.P., 1982), pp. 8, 16-17.

30. In Freud's account, morality is the repressed memory of punishment and threats from father. In technical terms, the super-ego emerges when the child represses his Oedipal fears and identifies with his father. See Sigmund Freud, The Ego and the Id (New York, Norton, 1962), trans. Joan Riviere, revised and edited by James Strachey. A clear discussion of these ideas is provided by Richard Wollheim in “The Last Phase," Sigmund Freud (Viking Press, New York, 1971), Chapter 7.

31. Anti-utilitarian philosophers typically reject the theory that conforming to a principle of morality involves weighing alternative reasons and balancing them. For example, see Joseph Raz on The Morality of Freedom (New York, Oxford U.P., 1986).

32. The following is a rare example of a discussion of internalization by a law and economics scholar:

... a player who had been punished in Tit-for-Tat fashion $\mathrm{x}$-times in succession for unprovoked defections in a Prisoner's Dilemma game, would, at that point, internalize the punishment. After internalization, the player would, like Pavlov's dog, automatically deduct the expected amount of punishment from the payoffs he previously perceived to be associated with his unprovoked defections. . . .

Robert Ellickson, "Bringing Culture and Human Frailty to Rational Actors: A Critique of Classical 
Law-and-Economics" (Feb. 1989, prepared for the Chicago-Kent Law Review Symposium on "Post-Chicago Law-and-Economics," p. 43).

33. These feelings manifest themselves in various behaviors that signal to others what the actor did and change the optimal strategies in games. For example, a person may prefer to cooperate in a game because involuntary emotional responses increase the risk of detection for "cheaters." See Robert Frank's account of emotional responses as signals in Chapters 1 and 3 of Passions within Reason: The Strategic Role of the Emotions (New York, Norton, 1988).

34. A summary of the positive theory of law is in Ronald Dworkin, "The Model of Rules," Taking Rights Seriously (1977), chapter 2.

35. This theory is vulnerable to the criticism that a norm might satisfy the positivist existence conditions in one community, whereas people in other communities regard it as thoroughly immoral. To illustrate, many tribes impose an obligation on their members to revenge the death of a relative, even though clan revenge seems abhorrent to most modern people. Thus critics have argued that a rule must satisfy certain minimal conditions of morality before it can be called a law, regardless of whether or not it satisfies positivist existence conditions. One of the grand, eloquent debates in jurisprudence concerned this subject. See Lon Fuller, "The Morality That Makes Law Possible," The Morality of Law (New Haven, Yale U.P., 1964), pp. 33-93, and "Positivism and Fidelity to Law-A Reply to Professor Hart," 71 Harvard Law Rev. 630 (1958); H. L. A. Hart, "Positivism and the Separation of Law and Morals," 71 Harvard Law Rev. 593 (1958).

36. A model with citations is found in my paper entitled, "Lapses, Conflict, and Akrasia in Torts and Crimes: Towards an Economic Theory of the Will," 11 International Review of Law and Economics $149-164$ (1991).

37. Max Weber, The Protestant Ethic and the Spirit of Capitalism (2nd ed., trans. Talcott Parsons, New York, Scribner, 1976).

38. See Robert Cooter, "Inventing Market Property: The Land Courts of Papua New Guinea," 25 Law and Society Review 759-802 (1991).

39. For example, Stewart Macaulay, "Private Legislation and the Duty to Read: Business Run by IBM Machine, the Law of Contracts, and Credit Cards," 19 Vanderbilt Law Review 1051 (1966); and Robert Ellickson, Order Without Law: How Neighbors Settle Disputes (Cambridge, MA, Harvard U.P., 1991).

40. Everyone benefits if the investment effect exceeds the exit effect.

41. The preeminent book on legal positivism is H. L. A. Hart, The Concept of Law (Oxford, Calendon Press, 1961). For a history, see Joseph Raz, The Concept of a Legal System (2nd ed., New York, Oxford U.P., 1980). The shortcomings of legal positivism need not concern us here.

42. The alignment theorem could be distinguished into weak, strong, and very strong forms, depending upon whether the alignment of private incentives for signaling with a local public good is a sufficient, necessary, or necessary and sufficient condition, respectively, for the evolution of a social norm. The very strong form is stated in the text.

43. See footnote 24

44. An interesting discussion of the extent to which animals have morality is found in Jane Goodall's "Order without Law," 5 J. Social \& Biological Structures 353-360 (1982). Also see Frans B. M. de Waal, "The Chimpanzee's Sense of Social Regularity and its Relation to the Human Sense of Justice," 34 American Behavioral Scientist 335-349 (1991).

45. An interesting discussion of business communities becoming committed to the wrong standards due to lack of information is in Alan O. Sykes, Policing Technical Barriers to Trade in Internationally Integrated Goods Markets (Brookings Institution, forthcoming). See his discussions of technical incompatibilities. Sykes is optimistic that private businesses can overcome these problems in time by voluntary standard setting, whereas he is pessimistic that governments can improve the situation by compulsory regulations.

46. Otherwise the cartel is not setting the price that maximizes the total profits of its members.

47. Robert Cooter, "Market Affirmative Action," Conference on Richard Epstein's Forbidden Grounds, San Diego, CA, December 1992, to appear in San Diego Law Review.

48. A perplexing question is how norms prescribing the subordination of a group of people arise in the community to which they belong. I have sexual discrimination in mind. I suspect that in order for a discriminatory norm to arise in a community that includes its victims, the injurers must 
monopolize the discussion from which the norm emerges. Another omitted topic is "stranger norms." Many significant norms exist in society that arise from repeated games in which the players remain strangers to each other. For example, driving on the highway involves interactions with unidentified motorists. A crucial fact is that each driver may be the injurer or the victim in an accident. Apparently, symmetry can generate efficient social norms in an anonymous repeated game. This process requires explaining.

49. "Strong utilitarianism" would hold that every efficient equilibrium in a game will evolve into a social norm.

50. Indeed, even powerful regulators have difficulty obtaining reliable information on costs from regulated industries. To illustrate, the electric power industry has strong incentives to misrepresent the cost of electricity to its regulator, who sets prices. 